\title{
The Voices of Graduates: Informing Faculty Practices to Establish Best Practices for Readying NCLEX-RN Applicants
}

\author{
Mary Hanson-Zalot*, Angela Gerolamo, Julia Ward \\ Thomas Jefferson University, Philadelphia, PA, USA \\ Email: *Mary.hanson-zalot@jefferson.edu
}

How to cite this paper: Hanson-Zalot, M., Gerolamo, A. and Ward, J. (2019) The Voices of Graduates: Informing Faculty Practices to Establish Best Practices for Readying NCLEX-RN Applicants. Open Journal of Nursing, 9, 125-136. https://doi.org/10.4236/ojn.2019.92012

Received: January 16, 2019

Accepted: February 15, 2019

Published: February 18, 2019

Copyright ( 2019 by author(s) and Scientific Research Publishing Inc. This work is licensed under the Creative Commons Attribution International License (CC BY 4.0).

http://creativecommons.org/licenses/by/4.0/

\begin{abstract}
Changes in the National Council of State Boards of Nursing along with other factors influence graduates' successful completion of a nursing program and the licensing examination. Literature is scarce in the area of examining student perceptions of preparing for and taking the NCLEX-RN examination. Our study sought to fill this gap in knowledge by conducting a focus group and interviews with individuals who passed the NCLEX-RN on their first attempt and those who did not. This was a descriptive qualitative study which used semi-structured interviews and a focus group to examine graduates' perceptions related to preparing for and taking the NCLEX-RN. Four themes emerged from the data: messages from faculty, preparation strategies, exam readiness, and the disconnection between pretest and intra-test experiences. Findings point towards the importance of implementing a variety of strategies to ensure that graduates successfully pass the NCLEX-RN.
\end{abstract}

\section{Keywords}

Students, NCLEX-RN Success, Qualitative Analysis

\section{Background}

Nursing is a dynamic, practice-based discipline that changes over time in response to advances in science and emerging evidence. The National Council of State Boards of Nursing (NCSBN) conducts a practice analysis every three years to identify the knowledge, skills and abilities of newly licensed registered nurses actively practicing in the profession. In 2011, when the practice analysis was conducted, the results of this survey were used to inform the development of the National Council Licensure Examination (NCLEX-RN) and in December 2012, 
the passing standard for test takers was raised from -0.16 logits to 0.00 logit. This change impacted all test candidates as of April 1, 2013 [1]. Typically, when the passing standard for the NCLEX-RN is raised, there is a slight decline in the national pass rate for all first-time test takers for the first year following the change in the passing standard [2]. Since October 1995 changes in the passing standard have never exceeded a 0.07 value [3]. The most recent change in the passing standard reflected a logit change of 0.16. Subsequent to this change; there was approximately a seven percent decrease in the national pass rate for first-time testing candidates. As of December, 2015 the NCSBN Board of Directors made the decision to maintain the passing standard at the current level of 0.00 logit through March 31, 2019. Nonetheless, faculty and students alike need to remain mindful of the rigor of the examination and adapt effective strategies for preparation and approach to the testing situation.

In addition to changes in the NCLEX-RN, other factors influence graduates' successful completion of a nursing program and the licensing examination. One study [4] described the complexities of nursing education and students' learning systems that ultimately influence success on the NCLEX-RN. In identifying measures to assist students with academic progression and examination readiness, she cautioned that some strategies employed, such as giving higher level questions on examinations, can actually be detrimental to success unless students are effectively prepared for the change. A frequent preparatory strategy is the administration of commercially available readiness tests. Results of these tests provide feedback to students on their areas of strengths and weaknesses so that remediation plans can be developed. Often times, such exams are administered late in a program allowing little time to "remediate" a student [5]. Contemporary studies conducted in the area of NCLEX-RN performance focus on the identification of predictors for program completion [6] or examination success [5] [7] [8]. Literature is scarce in the area of examining student perceptions of preparing for and taking the NCLEX-RN examination [9]. This study sought to fill this gap in knowledge by conducting a focus group and interviews with individuals who passed the NCLEX-RN on their first attempt and those who did not. Gathering and analyzing this information will enable nursing school administration and faculty to develop and implement data-informed strategies to prepare students for success on their first attempt taking the NCLEX-RN examination.

\section{Methods}

This descriptive qualitative study used semi-structured interviews and a focus group to examine graduates' perceptions related to preparing for and taking the NCLEX-RN. The three objectives of this study were to: 1) obtain an in-depth understanding of graduates' perceptions related to preparing for and taking the NCLEX-RN, 2) identify graduates' perceived challenges and if, and how expectations about the exam differ from their test taking experience, and 3) describe and 
compare the perceptions of graduates who were successful at their first attempt taking NCLEX and those who were not successful.

\subsection{Sample}

Between July 1, 2013 and September 30, 2013, the total number of graduates, traditional baccalaureate of nursing (BSN) and facilitated academic coursework track (FACT) graduates, at a college of nursing in an urban setting who took the NCLEX-RN was 252. Of these, 39 graduates failed the exam on their first attempt. The researchers began study recruitment by using systematic random sampling procedures to create two groups: 1) graduates who were successful on their first NCLEX-RN attempt and 2) graduates who were not successful on their first attempt. Thirty graduates from each group were invited to participate in a one-hour focus group via US Mail as well as by email invitation. Reminder email and US Mail invitations were sent after two weeks as the first contact attempt did not result in recruitment of 24 participants ( 12 for each group). Postal and e-mail addresses for the graduates were secured from the Alumni Office. Because this initial recruitment strategy did not yield sufficient participants, the researchers recruited participants from the May 2014 graduate pool and contacted potential study participants by telephone to conduct individual interviews. Thus, the sample shifted to a convenience sample using snowball sampling strategies. The researchers conducted a total of two rounds of recruitment for both the 2013 and 2014 graduate cohorts resulting in a sample of nine undergraduate program graduates who passed the NCLEX-RN on their first attempt and nine who failed on their first attempt. Table 1 provides a description of the sample. This study was considered exempt from the Institutional Review Board.

\subsection{Data Collection}

Prior to developing the interview guides, the researchers reviewed the nursing education literature for topics related to NCLEX-RN exam preparation, learning

Table 1. Description of participants, nursing program type, and year of graduationfrom nursing program.

\begin{tabular}{|c|c|c|}
\hline Participants & Nursing Program Type & $\begin{array}{l}\text { Year of Graduation from } \\
\text { Nursing Program }\end{array}$ \\
\hline \multirow{4}{*}{$\begin{array}{l}\text { Number of Participants } \\
\text { Successful Passing NCLEX } \\
\text { on First Attempt }(\mathrm{N}=9)\end{array}$} & $\begin{array}{l}\text { Accelerated Pathway to Master's Program } \\
\qquad(\text { APW) } N=2\end{array}$ & \multirow{4}{*}{$\begin{array}{l}2013 \mathrm{~N}=1 \\
2014 \mathrm{~N}=8\end{array}$} \\
\hline & Facilitated Academic Coursework Track & \\
\hline & $(\mathrm{FACT}) \mathrm{N}=4$ & \\
\hline & $\begin{array}{l}\text { Traditional Bachelor of Science in Nursing } \\
\text { (BSN) } \mathrm{N}=3\end{array}$ & \\
\hline \multirow{3}{*}{$\begin{array}{l}\text { Number of Participants } \\
\text { Not Successful Passing } \\
\text { NCLEX on First Attempt } \\
\qquad(\mathrm{N}=9)\end{array}$} & Accelerated Pathway to Master's Program & \multirow{3}{*}{$\begin{array}{l}2013 \mathrm{~N}=0 \\
2014 \mathrm{~N}=9\end{array}$} \\
\hline & ic - & \\
\hline & (FACT) $\mathrm{N}=4$ & \\
\hline
\end{tabular}


and test-taking strategies, and NCLEX-RN outcomes. The researchers created one interview guide for graduates who were successful taking the NCLEX-RN on their first attempt and a separate guide for those who were not. Once the guides were developed, three nurse educators with decades of teaching experience reviewed the guides to ensure that they contained priority topics and flow from general to focused questions (Polit \& Beck, 2012). Questions contained in the interview guides are stated below. Questions one through four, and question six were identical in both guides; Only question five was altered for graduates who were successful and who were not successful on their first NCLEX-RN attempt.

\section{Interview Questions for All Graduates}

Q1 What components (courses and/or clinical rotations) of the nursing curriculum prepared you best to approach the NCLEX-RN? Were some components not helpful? If so, what were they and why were they not helpful?

Q2 What types of teaching strategies used by faculty were most effective in preparing you for the NCLEX-RN? What strategies used by faculty were not helpful? Why?

Q3 How did you prepare for the NCLEX-RN? What study strategies did you use for the NCLEX-RN that you felt were most beneficial? Looking back, can you think of any strategies that you used that were not helpful for exam preparation? If so, why were they not helpful? Q4 What messages did you receive from faculty regarding preparation? Successful graduates: Q5 How did you know you were ready to take the NCLEX-RN?

Unsuccessful graduates: Q5 Did you feel ready to take the NCLEX-RN? Did you feel confident that you would pass? Why or why not?

Q6 Describe any feelings you had while taking the NCLEX-RN. How did you manage these feelings?

Data collection took place between February and March 2015. The researchers conducted one in-person focus group with four graduates who passed the NCLEX-RN. Because it was challenging to schedule a mutually agreeable time for interested graduates to participate in a focus group, the researchers conducted 30-minute individual telephone interviews with participants. The focus group and interviews were moderated by two of the authors of this manuscript. At the beginning of each interview/focus group, participants were informed that confidentiality would be maintained by not including names on the transcripts and securing all audiotapes and transcripts. The interviews and focus group were recorded with participant permission. Each participant signed a consent form and received a $\$ 15.00$ gift card for their participation.

The focus group and interview recordings were sent to a transcription agency for transcription. The researchers listened to the audio recordings when reviewing the accuracy of the transcripts. During this time, observations made during the focus group were documented to ensure that the transcripts reflect both spoken words, nonverbal gestures and emotions [10]. Further, researchers identified initial codes and documented their interpretations.

\subsection{Data Analysis}

NVivo was used to manage and analyze the data. To ensure confirmability of the 
data, each researcher reviewed the focus group transcript and a transcript of a participant who was not successful in taking the NCLEX-RN on their first attempt. Then, the researchers met to discuss impressions, identify descriptive codes and code the data. Confirmability of data is defined as the degree of neutrality or the extent to which findings are shaped by the respondents and not by reviewer bias or interest [11]. The researchers then coded all of the data. Once coding was complete, the researchers identified key themes, similarities and differences among graduates who were successful taking the NCLEX-RN on their first attempt and those who were not were also identified. A researcher not involved with data collection or analysis independently reviewed the data interpretations.

\section{Findings}

Four themes emerged from the data: messages from faculty, preparation strategies, exam readiness, and the disconnect between pretest and intra-test experiences.

\subsection{Messages from Faculty}

Successful and unsuccessful candidates who took the NCLEX-RN reported receiving similar messages from faculty. Hearing about the different types of items found on NCLEX-RN (multiple response, fill in the blank, ordered response, hot spotting) was helpful, along with the higher level of items (application and analysis). This reinforced to graduates the need to practice taking these types of items. Having samples of questions like medication dosage calculation and multiple response questions interspersed throughout lectures as well as on objective testing throughout the program was mentioned as beneficial. Messages of empathy from faculty such as, "You got this" and "We are here to help you" (both during and after graduation), and the sense that faculty were available was perceived as helpful by the graduates.

Graduates who were successful taking the NCLEX-RN the first time reported a message from faculty that was not helpful. The graduates who passed did not want to hear that the NCLEX-RN was designed to determine the graduates' ability or competency as a nurse.

\subsection{Preparation Strategies}

Preparation Strategies, the second theme was further divided into individual beneficial and nonbeneficial strategies, and program beneficial and nonbeneficial strategies. For those graduates who were successful the first time the individual beneficial strategies consisted of maintaining a set time each day to practice questions; setting a number of questions to do each time (a minimum of 75); and simulating the setting as a real test with no distractions such as fighting the urge to research content if the answer is not apparent to them or leaving the setting for several breaks. For unsuccessful test takers, individual nonbeneficial 
strategies were reviewing a minimal number of questions (10 to 25) per session and memorizing answers as opposed to understanding rationales. Successful graduates reported spending too much time studying one content area which caused some anxiety during the examination when questions related to the content least studied were presented. Students reflected on their preparation strategies:

"I just think that looking back on it, it was my own fault for not passing the first time around, just the way that I studied for it. No one told me to study-do ten in one sitting and then 10 again and then 20. But for some reason, I was preparing that way, and I was doing it wrong".

"I would sit at home just do maybe 20, 25 questions, look through the question and answers, answer them, and then I would just skim over the rationale and just see, 'Oh, $P$ ve got this $A$ wrong, and the answer should have been $B$ ', and I didn't really read why I was getting them wrong".

Beneficial program strategies were readily addressed by graduates from both groups. These included the use of a systematic approach to NCLEX-RN, infusing the preparation program (Kaplan) - throughout their plan of study; providing a concentrated course dedicated to review of content in their last semester of the nursing program; incorporating NCLEX-RN style questions on all objective examinations; strongly encouraging students to remediate all questions after taking the standardized examinations exams; simulating the NCLEX-RN setting by taking 75 or more questions at one time at regular intervals prior to the scheduled testing date.

"Of course, looking back, too, I m like, 'Oh, the faculty told us how to prepare to set you up to be successful. And they said, 'When you' re doing the Kaplan practice questions, do $X$ amount in one setting'. They say don't skip around and don' t-try not to do bursts of questions, like ten now, ten later. They say actually sit and prep the way you would if it was the actual test day".

Non-beneficial program preparation strategies identified by the graduates for both groups was that faculty who taught the NCLEX-RN preparation course (last course in the undergraduate program) were not experts in the content area and had difficulty explaining rationales to questions. Another strategy that was available to graduates but introduced later in the course was the Kaplan's Decision Tree technique to approach questions. Graduates felt that if they had known how to approach questions sooner it may have helped them prepare for the exam more effectively.

\subsection{Exam Readiness}

Faculty want to believe that they effectively have prepared graduates to take one of the most important examinations in their lifetime. Faculty also want the graduates to feel they are ready to take the examination as well. So the big question was, "Did the graduates feel ready to take the NCLEX-RN"? Collectively, graduates from both groups felt ready to take the NCLEX-RN describing efforts to get to that point through doing questions, exhausting all resources to the point 
that no more questions were available to them. Others felt that they were never completely ready to take the exam but prepared the best they could.

Confidence was a big indicator of readiness. Graduates from both groups felt that their preparation was sufficient so they had confidence they would be successful. Even those graduates who were unsuccessful the first time had what we describe as a false sense of readiness which they attributed to repeatedly meeting or exceeding the benchmark scores on the preparatory standardized examinations and question banks, giving them a sense of readiness. A lack of confidence also played into the minds of some graduates who despite practicing questions beyond the number faculty suggested, they never met the benchmark scores in some content areas.

Given the magnitude of potential content areas on the NCLEX-RN, some graduates thought they would never be completely ready because there was just too much content to study, some of which was addressed superficially if at all in their program. Some graduates described such anxiety about taking the NCLEX-RN that they scheduled the exam as soon as possible after graduation and took the exam despite not being fully ready to take it. Other graduates talked with their peers about the number of questions they practiced and realized that they had not done as many as their peers.

"As ready as I could have been for sure cause it was at that point I couldn't have done any more questions. I think-it seems like there was change into an average of so many numbers of questions I definitely went above and beyond that. I did way more than what was recommended. There was no way I could have studied any more for the NCLEX".

"I mean going into testing you don't feel a hundred percent but I felt like I was as ready as I could be and that there was nothing else I could have done to better prepare myself .

\subsection{Disconnect between the Pretest and Intra-Test Experience}

Graduates revealed a disconnect between the pretest and intra-test experience in that regardless of preparation, they all reported that it was "nothing like they had ever experienced before". Presently, students take examinations as a class experience. Since NCLEX-RN went to computerized adaptive testing, candidates take the exam individually. This experience then is a change from the norm experienced during school which affects some individuals. For the pretest experience there was an overall sense of anxiety among the 18 participants. One participant reported feeling physically sick prior to the exam and one said she cried prior to entering the test center.

Another disconnect that the graduates described was a false sense of readiness. They were assured and confident by the scores they received on the standardized examinations that it was almost a guarantee that they would pass the NCLEX-RN. In some cases, this feeling of confidence decreased the amount of studying they did or lessened the amount of questions they practiced.

"I guess based on the score that we got on that diagnostic after the review 
course, we were whatever percentage likely to pass the first time around, it made me feel like I was pretty prepared, at least minimally prepared to pass. And I think that caused me to decrease the amount that I was studying".

"I think the number that you got on that preparedness test helped people feel either good or bad, depending. That final test we took, I don't remember what I got, but was within the range that it needed to be and I was like, thank God. And then you would hear what your other classmates got and you were like, okay, $P \mathrm{~m}$ doing good".

"I still got the score I needed that said I was gonna be 93\% likely to pass when I didn't know some answers. So, like, why should it be any different with the boards"?

While some graduates thought they were prepared prior to the examination, they found out quickly into the examination that the questions were content either they had not studied or were weak in during the program. Graduates shared their experiences:

"For first attempt, I thought I was ready for the exam. When I took the exam, from the very first question, I found my preparation is not enough. And that was my first-very first impression when I took-after 10 or 15 questions in the first exam".

"I thought I was ready, but when I got questions I found I $m$ weak on, especially, the psych area. I got so many questions on that specialty area, I think, four or five".

"I was really nervous about the psych questions, because when I get there, I couldn't realize what-I could not recall what the real rationales are behind the questions".

While taking the NCLEX-RN, graduates did a great deal of self-talk, some of which was counterproductive. Graduates heard from peers who had passed the NCLEX-RN about the perceived number of alternate format style questions and the minimum number of questions they had prior to the computer screen going blank. Graduates anticipated that the minimum number is what they should be getting too and that this would translate into a passing score. They mentally tracked the type of questions and the number of questions that the computer posed to them as they moved through the examination.

"Talking to other people who had previously tested ... they said, 'If you' re getting alternate format questions, which probably means that you' re above the line of passing. And I was was getting questions that seemed to be very simple, and I was past the minimum passing number (75). I was concerned. And that affected me-my performance".

"At 80 I was like, alright, cause I had a lot of multiple choice questions and I was like, I gotta be doing good if $1 \mathrm{~m}$ getting a lot of these... Maybe they looked at my Kaplan scores and they just decided to give me what I normally get, which is like 150 questions. So I was like, maybe I m gonna make it to 150, and then it kept on going and 180 was my breaking point and I m like, oh my God, I failed. 
That's it. P $m$ done. And then I got upset at like 200 and then I focused more, and I felt like that helped me get through".

\section{Discussion and Recommendations}

This study contributes to the gap in knowledge related to the experience of nursing students as they prepare for the NCLEX. Consistent with the literature, our findings point towards the importance of implementing a variety of strategies to ensure that graduates successfully pass the NCLEX-RN [12]. At our college of nursing, there are some strategies that faculty are positioned to incorporate into the undergraduate program given the findings from this study, namely, strengthening programmatic resources; guiding graduates' preparation for the NCLEX-RN, simulating the NCLEX-RN experience, controlling self-talk, and hearing from veterans who employed successful strategies.

Our college adopted a nationally recognized program for NCLEX-RN success known as Kaplan ${ }^{\circledast}$ whereby we incorporated testing throughout the undergraduate program, with an intense focus on preparation prior to graduation. A key feature for success on the NCLEX-RN is remediation after all testing. While faculty repeatedly requested this and built remediation into each course with a Kaplan ${ }^{\circledR}$ component, graduates shared that they had too many competing demands throughout the program to follow through with this recommendation. Although students had to remediate as a requirement they did so with minimal effort, resulting in poor retention of the material.

Incorporating a standardized, reputable, NCLEX-RN program throughout the nursing program of study is a strategy that nursing school administration should consider to improve success on the NCLEX-RN [13]. Sending clear and consistent messages from faculty to students on how to use the program for maximum benefit in particular, concentrated remediation after each integrated test is supported by the literature [14] [15]. Providing instruction and practice on taking NCLEX-RN questions using the decision tree assist graduates to approach questions with confidence. Another valuable strategy that should be considered is developing a course devoted to NCLEX-RN preparation within the program of study that provides content review from faculty who are experts in those areas and can instruct students [15]. Finally, nursing school administrators should encourage faculty to participate in development programs that educate faculty on how to teach students to answer questions throughout the program, and not wait until the end of their nursing program.

Preparation for the licensure examination is critical to graduates' entry into practice. Increasingly, employers hire graduate nurses with licensure and are less likely to retain the graduate if unsuccessful after the first attempt. Being able to call oneself an "RN" may be the one rewarding accomplishment in a person's life. The pressure that is placed on those of us who have undertaken this process is enormous. Guiding graduates' preparation is part of the faculty role who advise graduates and teach in undergraduate nursing programs. Structure is important so much so that graduates should think of preparing for NCLEX-RN like 
going to the gym. Discipline is required. A routine of taking a set amount of questions (75 or more) frequently, if not daily, throughout the weeks prior to the test is key in simulating the NCLEX-RN experience. The questions should come from reputable sources and the graduate should use the decision tree method on how to approach questions. Reviewing content areas that the graduate deemed weak during their program and tackling questions on that content could help the graduate build confidence in that area [16].

Simulating the NCLEX-RN experience will help to lessen graduates' anxiety regarding the unfamiliar environment for this type of testing. Ideally, colleges of nursing should establish a setting within the college that mimics as many attributes of the NCLEX-RN testing process. Faculty should impart their state boards of nursing and testing site information to graduates so that they become aware of the expectations and be able to respond to any questions the graduates might have regarding the process.

Impart to graduates that timing of the NCLEX-RN matters [17]. Know your graduates. Consistently strong performers should schedule the exam early (if they have a disciplined action plan). Warn graduates against a false sense of readiness based solely on achieving the benchmark on standardized exams. Graduates who are less confident, should delay for a short period of time and work with a tutor. Counsel graduates who use accommodations in your program to request these same accommodations from their respective state boards of nursing.

Controlling self-talk is an important recommendation but may be the most difficult to control. Self-talk during testing can make or break a graduate's performance. Warn graduates about this phenomenon by telling them to expect the maximum of 265 questions. Discourage graduates from discussing with their peers who have not taken the NLCEX-RN the number of questions they took before the computer screen went blank. Whether or not they are getting alternate format questions (e.g. multiple response) or content that they were least sure of is irrelevant. They are still in the game.

Provide a forum for past graduates to address current senior students can be beneficial. Graduates are proud of the status of their university in the community and delight in returning to the campus with stories of how well they perform on hospital medication exams, in external NCLEX-RN review courses, and on clinical settings in comparison to graduates of other area universities and colleges. Sharing their experience may make the message more relatable to students about to embark on the NCLEX-RN [16].

\section{Conclusion}

When colleges of nursing produce graduates who pass the NCLEX-RN on the first attempt, their program quality shines. It is a boost for graduates and their alma mater. High recognition of passing rates locally, regionally, and nationally is valued in academia. To graduates: instill in them the belief that they are why 
we do, what we do and the rest will follow.

\section{Acknowledgements}

Publication made possible in part by support from the Thomas Jefferson University + Philadelphia University Open Access Fund.

\section{Conflicts of Interest}

The authors declare no conflicts of interest regarding the publication of this paper.

\section{References}

[1] National Council of State Boards of Nursing (2012) Report of Findings from the 2011 RN Nursing Knowledge Survey. Chicago, IL.

[2] Serembus, J.F. (2016) Improving NCLEX First-Time Pass Rates: A Comprehensive Program Approach. Journal of Nursing Regulation, 6, 38-44.

https://doi.org/10.1016/S2155-8256(16)31002-X

[3] National Council of State Boards of Nursing (2013) 2011 Nurse License Volume and NCLEX Examination Statistics. https://www.ncsbn.org/13_NCLEXExamStats_Vol57_final.pdf

[4] Carrick, J.A. (2011) Student Achievement and NCLEX-RN ${ }^{\circledast}$ Success: Problems That Persist. Nursing Education Perspectives, 32, 78-83.

https://doi.org/10.5480/1536-5026-32.2.78

[5] Simon, E.B., McGinnis, S.P. and Krauss, B.J. (2013) Predictor Variables for NCLEX-RN Readiness Exam Performance. Nursing Education Perspectives, 34, 18-24.

[6] Harding, M. (2010) Predictability Associated with Exit Examinations: A Literature Review. Journal of Nursing Education, 49, 493-497. https://doi.org/10.3928/01484834-20100730-01

[7] Penprase, B.B. (2013) Accelerated Second-Degree Nursing Students: Predictors of Graduation and NCLEX-RN ${ }^{\circledast}$ First-Time Pass Rates. Nurse Educator, 38, 26-29. https://doi.org/10.1097/NNE.0b013e318276df16

[8] Romeo, E.M. (2013) The Predictive Ability of Critical thinking, Nursing GPA, and SAT Scores on First-Time NCLEX-RN ${ }^{\circledR}$ Performance. Nursing Education Perspectives, 34, 248-253.

[9] Pabst, M.K., Strom, J. and Riess, P.J. (2009) Use of Focus Groups to Elicit Student Perception of NCLEX-RN ${ }^{\circledR}$ Preparation. Journal of Nursing Education, 49, 534-537. https://doi.org/10.3928/01484834-20090524-04

[10] Polit, D.F. and Beck, C.T. (2012) Nursing Research: Generating and Assessing Evidence for Nursing. 9th Edition, Wolters Kluwer, Philadelphia.

[11] Lavin, J. and Rosario-Sim, M.G. (2013) Understanding the NCLEX: How to Increase Success on Revised the 2013 Examination. Nursing Education Perspectives, 34, 196-198.

[12] Lincoln, Y. and Guba, E. (1985) Naturalistic Inquiry. Sage Publications, Beverly Hills, CA.

[13] Czekanski, K., Mingo, S. and Piper, L. (2018) Coaching to NCLEX-RN Success: A Postgraduation Intervention to Improve First-Time Pass Rates. Journal of Nursing Education, 57, 561-565. https://doi.org/10.3928/01484834-20180815-10 
[14] Harvilla, E., Zbegner, D. and Victor, J. (2018) Exploring Predictors of NCLEX-RN Success: One School's Search for Excellence. Journal of Nursing Education, 57, 554-556. https://doi.org/10.3928/01484834-20180815-08

[15] Pullen, R. (2017) A Prescription for NCLEX-RN Success. Nursing, 47, 19-24. https://doi.org/10.1097/01.NURSE.0000515520.69667.15

[16] Carr, S. (2011) NCLEX-RN Pass Rate Peril: One School's Journey through Curriculum Revision, Standardized Testing, and Attitudinal Change. Nursing Education Perspectives, 32, 384-388. https://doi.org/10.5480/1536-5026-32.6.384

[17] Draper, J. and Stein, A.M. (2000) 6 Tips on Preparing for the NCLEX-RN Exam. Imprint, 47, 51-52. 